\title{
Analisa Alternatif Revitalisasi Pasar Gubeng Masjid Surabaya Dengan Metode Highest and Best Use
}

\author{
Marsha Swalia Mustika dan Christiono Utomo \\ Jurusan Teknik Sipil, Fakultas Teknik Sipil dan Perencanaan, Institut Teknologi Sepuluh Nopember (ITS) \\ Jl. Arief Rahman Hakim, Surabaya 60111 \\ email: christiono@ce.its.ac.id
}

\begin{abstract}
Abstrak - Dalam era globalisasi ini banyak bermunculan pasar-pasar modern yang dibangun dengan segala kelebihan dan fasilitasnya. Munculnya pasar-pasar modern membuat keberadaan pasar tradisional tersudut, tidak terkecuali Pasar Gubeng Masjid Surabaya. Namun keberadaan pasar yang strategis yaitu dekat dengan perkantoran, hotel dan pusat perbelanjaan, serta stasiun kereta api membuat pasar tersebut memiliki potensi untuk dikembangkan menjadi properti yang memberikan nilai lahan tertinggi dan terbaik. Oleh karena itu, perlu dilakukan analisa Highest and Best Use (HBU) yang dapat memberikan masukan untuk melakukan investasi terbaik.

Analisa HBU ini menggunakan empat kriteria yaitu secara fisik dimungkinkan, secara legal diizinkan, secara finansial layak, dan memiliki produktivitas maksimum. Alternatif yang memiliki produktivitas maksimum tersebut dapat dijadikan sebagai nilai lahan tertinggi dan terbaik pada lahan Pasar Gubeng Masjid Surabaya.

Dari hasil penelitian didapatkan alternatif yang menghasilkan nilai lahan tertinggi dan produktivitas maksimum adalah alternatif pengembangan mix use pasar dengan pusat perbelanjaan.. Nilai lahan yang didapatkan $R p$ 46.946.524,- $/ \mathrm{m}^{2}$ dengan produktivitas meningkat sebesar $312 \%$.
\end{abstract}

Kata kunci-lahan, highest and best use, pasar Gubeng Masjid Surabaya , properti komersial

\section{LATAR BELAKANG}

$\mathrm{K}$ EBERADAAN pasar modern semakin pesat di Indonesia. Di beberapa kota seperti Surabaya sudah banyak terdapat mini market, supermarket bahkan hypermarket. Keadaan ini membuat pasar tradisional mengalami penurunan karena kalah bersaing dengan pasar modern yang memiliki fasilitas yang memadai. Oleh karena itu, saat ini banyak masyarakat lebih memilih berbelanja di pasar modern, terutama masyarakat di ekonomi menengah keatas. Tidak terkecuali pada Pasar Gubeng Masjid Surabaya yang terletak di Jalan Gubeng Masjid Surabaya.

Kemunculan pasar-pasar modern membuat keberadaan pasar tradisional tersudut, tidak terkecuali Pasar Gubeng Masjid Surabaya. Namun keberadaan pasar yang strategis yaitu dekat dengan perkantoran, hotel dan pusat perbelanjaan, serta stasiun kereta api membuat pasar tersebut memiliki potensi untuk dikembangkan menjadi properti yang memberikan nilai lahan tertinggi dan terbaik.

Oleh karena itu, perlu dilakukan analisa Highest and Best Use (HBU), yaitu penggunaan dari suatu tanah kosong atau peningkatan suatu properti yang secara fisik memungkinkan, secara legal diijinkan, layak secara finansial dan memiliki produktifitas maksimum [1].

\section{II.PENELITIAN TERDAHULU}

Penelitian [2] dan memiliki persamaan berupa objek penelitian yang merupakan objek dengan lahan telah difungsikan menjadi bangunan terminal Gadang di kota Malang lalu dianalisa untuk mengetahui penggunaan terbaik dan tertinggi dari lahan yang telah digunakan. Sedangkan pada penelitian [3] mengambil objek lahan yang sudah tidak difungsikan lagi sebagai SPBU Biliton dan dianalisa untuk dijadikan properti komersil. Penelitian [4] dan [5] mengambil objek penelitian lahan kosong. Lahan tersebut dianalisa penggunaannya untuk dijadikan properti komersil. Penelitian tersebut hanya berbeda pada lokasi lahan.

Berdasarkan beberapa penelitian terdahulu terdapat perbedaan dan persamaan dengan paper ini. Persamaan paper ini dengan penelitian [2] dan [3] adalah berupa objek penelitian yang telah difungsikan menjadi suatu bangunan, namun perbedaannya terletak pada objek penelitian tugas akhir ini berupa lahan Pasar Gubeng Masjid Surabaya. Pada penelitian paper ini lahan diasumsikan sebagai lahan kosong karena kondisi fisik bangunan yang kurang memadai.

\section{METODOLOGI}

Penelitian ini menggunakan konsep Highest Best Use (HBU) untuk menganalisa pemanfaatan lahan pada Pasar Gubeng Masjid Surabaya yang memiliki luas lahan seluas $3448 \mathrm{~m}^{2}$ agar dapat diketahui jenis alternatif pengembangan yang menghasilkan nilai lahan tertinggi dan terbaik berdasarkan aspek legal, aspek fisik, aspek finansial, serta produktivitas maksimum.

Tabel 1.

Pengelompokkan Indikator dan Jenis Data

\begin{tabular}{|c|c|c|c|c|}
\hline No & Variabel & Klasifikasi & Tipe data & Sumber Data \\
\hline 1 & $\begin{array}{l}\text { Penentuan } \\
\text { Alternatif }\end{array}$ & $\begin{array}{l}\text { Alternatif } \\
\text { penggunaan } \\
\text { lahan }\end{array}$ & & $\begin{array}{l}\text { Wawancara } \\
\text { dan Kuisioner }\end{array}$ \\
\hline 2 & Legal & $\begin{array}{ll}\text { a. } & \text { Zoning } \\
\text { b. } & \text { Building } \\
& \text { code, yaitu } \\
\text { GSB, KDB, } \\
\text { KDH }\end{array}$ & Sekunder & $\begin{array}{l}\text { Badan } \\
\text { Perencanaan } \\
\text { Pembangunan } \\
\text { Kota } \\
\text { Surabaya } \\
\text { (BAPEKO) } \\
\text { dan } \\
\text { Pemerintah } \\
\text { Kota } \\
\text { Surabaya }\end{array}$ \\
\hline 3 & Fisik & $\begin{array}{l}\text { a. Ukuran } \\
\text { Lahan } \\
\text { b. Bentuk } \\
\text { Lahan } \\
\text { c. Aksesbilitas }\end{array}$ & Primer & $\begin{array}{l}\text { 1. Pengamatan } \\
\text { langsung } \\
\text { 2. Stakeholder } \\
\text { lahan }\end{array}$ \\
\hline
\end{tabular}




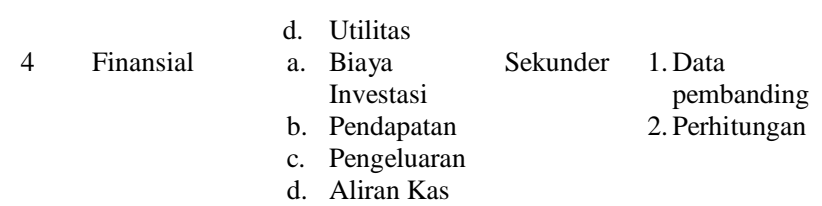

\begin{tabular}{|c|c|c|c|}
\hline & Produktivitas & Nilai lahan & Hasil analisa \\
\hline 5 & Maksimum & & finansial \\
\hline
\end{tabular}

\section{A. Data Penelitian}

Dalam penelitian ini terdapat dua sumber data yaitu data primer dan data sekunder. Rincian pengelompokan data dapat dilihat pada Tabel 1. Data yang diperoleh tersebut kemudian dilakukan analisis HBU sesuai aspek fisik, aspek legal, aspek finansial dan produktifitas maksimum.

\section{B. Analisa Data}

Dari data yang terkumpul, dilakukan analisa Highest and Best Use (HBU) yang meliputi aspek legal, aspek fisik, aspek finansial, dan produktivitas maksimum.

Dalam Analisa legal, alternatif pengembangan properti akan dianalisa kesesuaiannya menurut hukum meliputi analisa penggunaan properti sesuai dengan peruntukkan lahan (zoning) dan peraturan pemerintah mengenai bangunan, yaitu GSB, KDB, KLB, KDH, dan ketinggian bangunan.

Sedangkan analisa aspek fisik meliputi bentuk dan ukuran lahan, aksesibilitas dan sara publik, serta ketersediaan utilitas.

Alternatif yang dinyatakan lulus berdasarkan analisa kelayakan fisik, selanjutnya akan dianalisa kelayakan finansialnya. Pada analisa kelayakan finansial ini akan ditentukan lingkup pada masing-masing alternatif properti agar dapat diestimasi dan sisi investasi, pendapatan, pengeluaran, dan Net Present Value (NPV).

Setelah melakukan analisa finansial selanjutnya dilakukan analisa untuk mengetahui produktivitas maksimum dari ketiga alternatif pengembangan. Metode yang digunakan untuk menganalisa produktifitas maksimal adalah melalui pendekatan pendapatan (Income Approach) pendekatan tersebut dipergunakan karena penilaian dilaksanakan terhadap properti yang dapat rnenghasilkan pendapatan.

\section{ANALISA DATA}

\section{A. Penetapan Alternatif Pengembangan}

Dari hasil wawancara dan pengisian kuisioner diperoleh alternatif pengembangan single use dan multi use. Alternatif pengembangan single use yaitu berupa revitalisasi pasar, dimana lahan tetap dijadikan pasar namun dengan konsep yang berbeda yaitu pasar lebih modern serta lebih nyaman sehingga dapat menarik minat pembeli. Sedangkan alternatif multi use yaitu penggabungan pasar dengan pusat perbelanjaan/Trade Centre serta penggabungan Pasar dengan perkantoran. Dalam hal ini fungsi pasar masih tetap ada dan dipertahankan yaitu dengan prosentase $40 \%$ dan $60 \%$ sisanya untuk perkantoran ataupun pusat perbelanjaan.

\section{B. Analisa Aspek Legal}

Berdasarkan persyaratan Rencana Tata Ruang Kota Surabaya pada lokasi obyek penelitian peruntukan lahan pada daerah tersebut adalah untuk perdagangan atau komersial, memiliki ketinggian bangunan maksimum 5 lantai, GSB 3m,
KDB 60\%, KLB 280\%, dan KDH 20\%. Berdasarkan analisa maka pada lahan Pasar Gubeng Masjid Surabaya dapat digunakan sebagai bangunan komersial 5 lantai dengan luas lantai dasar sebesar $1961,5 \mathrm{~m}^{2}$. dan luas lantai bangunan maksimum sebesar 9654,4 $\mathrm{m}^{2}$ untuk memaksimalkan ketinggian bangunan.

\section{Analisa Aspek Fisik}

Berdasarkan hasil analisa dan pembahasan dari beberapa segi pada aspek fisik diperoleh kesimpulan bahwa lahan penelitian terletak pada wilayah yang cukup strategis karena memiliki aksesibilitas yang mudah dijangkau dan utilitas umum yang memadai. Selain itu, lahan berada pada kawasan perdagangan dan fasilitas umum sehingga memungkinkan untuk dilakukan pengembangan.

\section{D.Analisa Aspek Finansial}

Kelayakan secara finansial dilakukan melalui analisa aliran kas, yaitu biaya investasi, pendapatan dan pengeluaran. Dikarenakan lahan Pasar Gubeng Masjid terdapat bangunan diatasnya dan diasumsikan sebagai lahan kosong maka perlu adanya biaya pembongkaran bangunan.

\section{1) Biaya Investasi}

Perencanaan biaya investasi yang diperlukan dalam perencanaan bangunan ini diperhitungkan dengan melakukan pendekatan (perencanaan biaya secara kasar) untuk memberikan gambaran biaya yang harus dikeluarkan untuk pembangunan. Adapun rencana biaya yang diperlukan dapat dilihat pada Tabel 2

Tabel 2.

Perencanaan Biaya Investasi

\begin{tabular}{|c|c|c|c|c|}
\hline No & Jenis Biaya & $\begin{array}{c}\text { Pasar } \\
(\mathrm{Rp})\end{array}$ & $\begin{array}{l}\text { ternatif Pengemban } \\
\text { Pasar dan } \\
\text { Perbelanjaan } \\
\text { (Rp) }\end{array}$ & $\begin{array}{c}\text { Pasar dan } \\
\text { Perkantoran } \\
(\mathrm{Rp})\end{array}$ \\
\hline 1 & $\begin{array}{l}\text { Biaya } \\
\text { Pembongkaran }\end{array}$ & $112,855,575.00$ & $112,855,575.00$ & $112,855,575.00$ \\
\hline 2 & $\begin{array}{l}\text { Biaya Tanah } \\
\text { Biaya }\end{array}$ & $39,301,506,710.4$ & $39,301,506,710.4$ & $39,301,506,710.42$ \\
\hline $\begin{array}{l}3 \\
4\end{array}$ & $\begin{array}{l}\text { Konstruksi } \\
\text { Biaya Jasa }\end{array}$ & $25,747,901,368.5$ & $49,518,518,876.9$ & $56,255,318,570.3$ \\
\hline 4 & $\begin{array}{l}\text { Profesi } \\
\text { Biaya }\end{array}$ & $772,437,041.06$ & $1,485,555,566.31$ & $1,687,659,557.11$ \\
\hline 5 & $\begin{array}{l}\text { Administrasi } \\
\text { Biaya Lain- }\end{array}$ & $257,479,013.69$ & $495,185,188.77$ & $562,553,185.70$ \\
\hline 6 & lain & $1,287,395,068.43$ & $2,475,925,943.85$ & $2,812,765,928.52$ \\
\hline Tot & Biaya Investasi & $67,366,719,202.0$ & $93,276,692,286.2$ & $100,619,803,952$. \\
\hline
\end{tabular}

\section{2) Pendapatan}

Perencanaan pendapatan kotor bersumber dari penjualan atau penyewaan, service charge dan pendapatan tambahan tergantung dari jenis propertinya. Sedangkan pendapatan efektif dilakukan dengan mengurangi pendapatan kotor dengan tingkat kekosongan pada masing-masing alternatif. Tingkat kekosongan dihitung dengan mengalikan prosentase tingkat kekosongan dengan pendapatan kotor.

3) Pengeluaran

Biaya yang dikeluarkan pada tiap alternatif digunakan untuk membiayai biaya listrik, biaya air, biaya gaji pegawai dan biaya pemeliharaan bangunan. biaya listrik 
dan air disesuaikan dengan tarif dasar listrik dan tarif air yang berlaku di Surabaya [6]

\section{4) Aliran Kas}

Alternatif properti dikatan layak apabila memiliki nilai NPV lebih besar dari nol. Dari hasil analisa aspek finansial diperoleh alternatif property yang layak yaitu pasar dengan nilai NPV sebesar Rp. 30.217.134.141,43.pasar dan pusat perbelanjaan dengan NPV sebesar Rp.158.270.794.239,09.- serta pasar dan perkantoran dengan NPV Rp. 92.965.922.520

\section{E. Produktifitas Maksimum}

Setelah perhitungan aspek finansial, tahapan selanjutnya adalah menghitung produktivitas maksimum pada masingmasing alternatif pengembangan. Berikut ini adalah produktivitas maksimum dari masing-masing alternatif pengembangan :

Tabel 3.

Produktifitas Lahan untuk Setiap Penggunaan Alternatif

\begin{tabular}{|c|c|c|c|c|}
\hline Kode & Uraian & $\begin{array}{l}\text { Pasar } \\
(\mathrm{Rp})\end{array}$ & $\begin{array}{c}\text { Alternatif } \\
\text { Pasar dan } \\
\text { Perbelanjaan } \\
\text { (Rp) }\end{array}$ & $\begin{array}{c}\text { Pasar dan } \\
\text { Perkantoran } \\
(\mathrm{Rp})\end{array}$ \\
\hline 1 & Nilai Properti & $\begin{array}{r}59,318,217, \\
324\end{array}$ & $\begin{array}{r}215,846,799 \\
591\end{array}$ & $\begin{array}{r}156,920,966, \\
912\end{array}$ \\
\hline 2 & Nilai Investasi & $\begin{array}{r}67,366,719 \\
202\end{array}$ & $\begin{array}{r}93,276,692,2 \\
86\end{array}$ & $\begin{array}{r}100,619,803 \\
952\end{array}$ \\
\hline 3 & Biaya Tanah & $\begin{array}{r}39,301,506 \\
710\end{array}$ & $\begin{array}{r}39,301,506,7 \\
10\end{array}$ & $\begin{array}{r}39,301,506,7 \\
10\end{array}$ \\
\hline 4 & Nilai Bangunan & $\begin{array}{r}28,065,212 \\
492\end{array}$ & $\begin{array}{r}53,975,185,5 \\
76\end{array}$ & $\begin{array}{r}61,318,297,2 \\
42\end{array}$ \\
\hline 5 & Nilai Lahan & $\begin{array}{r}31,253,004 \\
832\end{array}$ & $\begin{array}{r}161,871,614 \\
015\end{array}$ & $\begin{array}{r}95,602,669,6 \\
70\end{array}$ \\
\hline 6 & Nilai Lahan $/ \mathrm{m}^{2}$ & $9,064,097$ & $46,946,524$ & $27,726,992$ \\
\hline 7 & $\begin{array}{l}\text { Harga Lahan } \\
\text { Awal } / \mathrm{m}^{2}\end{array}$ & $11,398,349$ & $11,398,349$ & $11,398,349$ \\
\hline 8 & Produktifitas & $-20 \%$ & $312 \%$ & $143 \%$ \\
\hline
\end{tabular}

Berdasarkan perhitungan nilai lahan pada Tabel 3, nilai lahan tertinggi didapat dari alternatif pengembangan berupa pasar dan pusat perbelanjaan sebesar Rp 46.946.524/m² dengan produktivitas meningkat sebesar $312 \%$.

\section{KESIMPULAN}

Dari analisa Highest and Best Use yang dilakukan pada Pasar Gubeng Masjid Surabaya diperoleh kesimpulan bahwa pasar yang memiliki luas lahan sebesar $3448 \mathrm{~m}^{2}$ ini dapat dikembangkan menjadi bangunan komersial dengan jumlah lantai maksimum 5 lantai dengan luas dasar bangunan sebesar $1961,5 \mathrm{~m}^{2}$.

Ketiga jenis alternatif pengembangan, yaitu Pasar dengan konsep modern (single use), dan alternatif pengembangan multi use berupa Pasar dan Perkantoran, serta Pasar dan Pusat Perbelanjaan memenuhi aspek legal, fisik dan finansial. Dengan hasil akhir bahwa alternatif pengembangan lahan sebagai Pasar dan Pusat Perbelanjaan merupakan alternatif penggunaan terbaik karena memiliki nilai lahan sebesar Rp 46.946.524,-/ $/ \mathrm{m}^{2}$ dari nilai lahan awal $\mathrm{Rp} 11.398 .349,-/ \mathrm{m}^{2}$.
[1] B. Harianto and W. Hidayati, Konsep Dasar Penilaian Properti Edisi Pertama, Yogyakarta: BPFE, 2003.

[2] K. P. Negara, Analisa Penggunaan Tertinggi dan Terbaik pada Lahan Eks Terminal Gadang di Kota Malang. Tugas Akhir Program Studi Teknik Sipil, Surabaya: FTSP - ITS, 2010.

[3] T. D. A. Rasyid and C. Utomo, "Analisa Highest and Best Use (HBU) pada Lahan Bekas SPBU Biliton, Surabaya," Jurnal Teknis ITS, vol. 2, no. 2, pp. D181-D185, 2013.

[4] B. Anggarawati and C. Utomo, "Analisa Penggunaan Lahan Kawasan Komersial Perumahan Citra Raya, Surabaya dengan Metode Highest and Best Use," Jurnal Teknik ITS, vol. II, no. 2, pp. D39-D41, 2013.

[5] F. V. Faradiany and C. Utomo, "Analisa Highest and Best Use pada Lahan Kosong di Jemur Gayungan II, Surabaya," Jurnal Teknik ITS, vol. III, no. 2, pp. C61-C63, 2014.

[6] H. Poerbo, Tekno Ekonomi Bangunan Bertingkat Banyak, Jakarta: Djambatan, 1998. 